\title{
Commentary \\ Clinical trials update of the European Organization for Research and Treatment of Cancer Breast Cancer Group
}

\author{
Emiel J Th Rutgers ${ }^{1}$, Philip Meijnen ${ }^{2}$ and Hervé Bonnefoi ${ }^{3}$
}

\begin{abstract}
${ }^{1}$ Chairman of the EORTC Breast Cancer Group and Principal Investigator of the EORTC 10981-22023 AMAROS trial, Department of Surgery, The Netherlands Cancer Institute - Antoni van Leeuwenhoek Hospital, Amsterdam, The Netherlands

${ }^{2}$ Research Fellow and Coordinator of the EORTC 10981-22023 AMAROS trial, Department of Surgery, The Netherlands Cancer Institute - Antoni van Leeuwenhoek Hospital, Amsterdam, The Netherlands

${ }^{3}$ Secretary of the EORTC Breast Cancer Group and Principal Investigator of the EORTC 10994 p53 trial, Department of Medical Oncology, University Hospital of Geneva, Switzerland
\end{abstract}

Corresponding author: Emiel J Th Rutgers, e.rutgers@nki.nl

Published: 16 June 2004

Breast Cancer Res 2004, 6:165-169 (DOI 10.1186/bcr906)

(C) 2004 BioMed Central Ltd

\begin{abstract}
The present clinical trial update consists of a review of two of eight current studies (the 10981-22023 AMAROS trial and the 10994 p53 trial) of the European Organization for Research and Treatment of Cancer Breast Cancer Group, as well as a preview of the MIND-ACT trial. The AMAROS trial is designed to prove equivalent local/regional control for patients with proven axillary lymph node metastasis by sentinel node biopsy if treated with axillary radiotherapy instead of axillary lymph node dissection, with reduced morbidity. The p53 trial started to assess the potential predictive value of p53 using a functional assay in yeast in patients with locally advanced/inflammatory or large operable breast cancer prospectively randomised to a taxane regimen versus a nontaxane regimen.
\end{abstract}

Keywords: adjuvant chemotherapy, breast neoplasm(s), clinical trials, p53, sentinel node biopsy

\section{Introduction}

The European Organization for Research and Treatment of Cancer (EORTC) Breast Cancer Group is currently running eight studies: four randomised phase III trials, three phase II trials and one survey. In 2003, the Breast Cancer Group entered 1003 patients in these studies via 87 active participating centres. Table 1 presents a summary of the current open studies. The two most important studies will be reviewed here.

Another important trial that is in preparation and will be open in the near future is the MIND-ACT trial: a prospective, randomised study in node-negative breast cancer patients with two aims. The first is to test the performance of the gene prognosis signature (70-gene classifier) in comparison with the common clinicpathologic criteria as a new prognostic tool that will reduce the risk of overtreatment with the correct identifica- tion of patients who need adjuvant chemotherapy. The second aim is to evaluate a docetaxel + capecitabine (nonanthracycline-based) regimen as a superior alternative to an anthracycline-based regimen, for high-risk nodenegative breast cancer.

\section{The EORTC 10981-22023 AMAROS trial}

Until a few years ago an important part in staging breast cancer patients was the axillary lymph node dissection (ALND). Evidence has emerged that the sentinel node biopsy procedure by lymphatic mapping is an equivalent staging procedure to ALND [1-3]. The introduction of a new surgical technique requires a process of qualitycontrolled implementation (preferably by treating patients in prospective studies) in order not to jeopardise, but to improve the level of care gained by the ALND, as has been achieved by the implementation of breast-conserving surgery [4]. Only in this way can the questions regarding

AMAROS = After Mapping of the Axilla: Radiotherapy or Surgery; ANLD = axillary lymph node dissection; EORTC = European Organization for Research and Treatment of Cancer; MIND-ACT = Microarray in Node Negative Disease and Anthracycline Chemotherapy or Taxane; PCR = polymerase chain reaction; $\mathrm{PFS}=$ progression-free survival. 
Table 1

\begin{tabular}{|c|c|c|c|c|}
\hline Trial number & Study title & $\begin{array}{l}\text { Start } \\
\text { date }\end{array}$ & $\begin{array}{l}\text { Required } \\
\text { number of } \\
\text { patients }\end{array}$ & $\begin{array}{l}\text { Total } \\
\text { randomised/ } \\
\text { registered on } \\
1 \text { April } 2004\end{array}$ \\
\hline $10981-22023$ & AMAROS study - After Mapping of the Axilla: Radiotherapy or Surgery & 15 February 2001 & 3485 & 1133 \\
\hline 10994 & $\begin{array}{l}\text { p53 study - first prospective intergroup translational research trial } \\
\text { assessing the potential predictive value of p53 using a functional assay in } \\
\text { yeast in patients with locally advanced/inflammatory or large operable } \\
\text { breast cancer prospectively randomised to a taxane regimen versus a } \\
\text { nontaxane regimen (BIG number 00-01) }\end{array}$ & 14 March 2001 & 1440 & 863 \\
\hline 10995-16999 & $\begin{array}{l}\text { A randomised phase II study of CMF in combination with anti-cerbB2 } \\
\text { antibody (Herceptin }{ }^{\circledR} \text { ) in women with metastatic cancer }\end{array}$ & 5 February 2002 & 66 & 32 \\
\hline $10001-160010$ & $\begin{array}{l}\text { A randomised phase } I I \text { trial evaluating the efficacy of capecitabine and } \\
\text { vinorelbine in anthracycline and taxane pretreated metastatic breast cancer }\end{array}$ & 17 September 2002 & 72 & 38 \\
\hline 10002 & $\begin{array}{l}\text { A survey of the BIG (BIG 03-98) to assess the attitude toward the risk of } \\
\text { loss of fertility related to adjuvant therapies for patients with early breast } \\
\text { cancer aged younger than } 35 \text { years }\end{array}$ & 5 May 2003 & 385 & 51 \\
\hline 10011 & $\begin{array}{l}\text { HERA study - a randomised three-arm multicentre comparison of } 1 \text { year } \\
\text { and } 2 \text { years of Herceptin }{ }^{\circledR} \text {, versus no Herceptin }{ }^{\circledR} \text { in women with } \\
\text { HER2-positive primary breast cancer who have completed adjuvant } \\
\text { chemotherapy (BIG 01-01/EORTC 10011) }\end{array}$ & $\begin{array}{l}\text { BIG, December 2001; } \\
\text { EORTC, March } 2002\end{array}$ & 4482 & $\begin{array}{l}\text { EORTC BCG, } \\
143 ; \text { total, } 3555\end{array}$ \\
\hline 10021 & $\begin{array}{l}\text { An EORTC randomised, double-blind, placebo-controlled, phase II } \\
\text { multicentre trial of anastrozole (Arimidex) in combination with ZD1839 } \\
\text { (Iressa) or placebo in patients with advanced breast cancer }\end{array}$ & 28 May 2003 & 108 & 2 \\
\hline 10031 & $\begin{array}{l}\text { SOFT trial - intergroup study IBCSG } 24 \text { 02/BIG 2-02/EORTC } 10031 \text {. } \\
\text { A phase III trial evaluating the role of ovarian function suppression and the } \\
\text { role of exemestane as adjuvant therapies for premenopausal women with } \\
\text { endocrine-responsive breast cancer tamoxifen versus ovarian function } \\
\text { suppression + tamoxifen versus ovarian function suppression + exemestane }\end{array}$ & 14 January 2004 & 3000 & $\begin{array}{l}\text { EORTC BCG, } 0 \\
\quad \text { total, } 21\end{array}$ \\
\hline
\end{tabular}

BIG, Breast International Group; CMF, cyclophosphamide methotrexate and 5-fluorouracil; HERA, HERceptin ${ }^{\circledR}$ adjuvant; SOFT, Suppression of Ovarian Function Trial; IBCSG, International Breast Cancer Study Group.

the importance of different technical aspects and the questions on the clinical implications be answered.

The EORTC 10981-22023 AMAROS trial is a phase III study comparing a complete ALND with radiotherapy to the axilla in sentinel node-positive patients, whereas sentinel node-negative patients are followed for the endpoints of the study as well (Fig. 1). Patients enrolled on the trial must have an operable invasive breast cancer greater than $5 \mathrm{~mm}$ and less than $3 \mathrm{~cm}$, without clinically suspect regional lymph nodes. This intergroup study, which first enrolled patients in February 2001, is coordinated by the EORTC Breast Cancer Group in collaboration with the EORTC Radiotherapy Group, the BOOG (Breast Cancer Research Group) from The Netherlands and, in the near future, with former Axillary Lymphatic Mapping Against Nodular Axillary Clearance centres from the UK.

The main objective of the trial is to prove equivalent lymph node metastasis by sentinel node biopsy if treated with axillary radiotherapy instead of axillary lymph node dissection, with reduced morbidity. A second objective is to investigate whether adequate axillary control can be obtained by not subjecting patients with a negative sentinel lymph node to ALND.

As of 1 May, 18 institutes have included 1173 patients. It is assumed that the axillary recurrence-free rate in the ALND treatment group at 5 years equals 98\%, and the aim of this study is to show that the axillary recurrence-free rate in the radiotherapy group at 5 years is not less than $96 \%$. Given the ratio of 40 positive patients/60 negative patients, a total of 3485 patients are required to complete this study. The ratio to date of 35/63 (taking into account a $2 \%$ nonidentification rate) leads to a slight adjustment of the total number of patients needed. The study will at least be continued up to 2006 .

In order to ensure that the trial results are not compromised by the use of improper techniques, or by a 
Figure 1

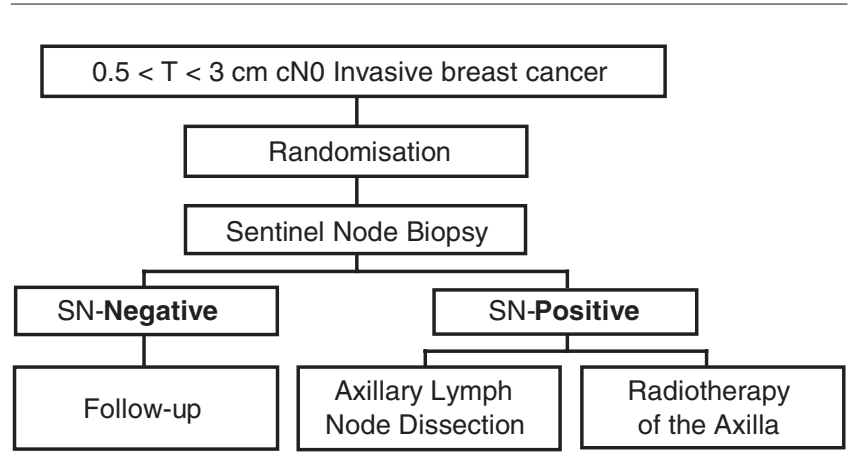

Treatment scheme of the European Organization for Research and Treatment of Cancer 10981-22023 AMAROS trial. cNO, clinically negative lymph nodes; SN, sentinel node.

large variation in the quality of the treatment techniques used, the protocol provides guidelines for the sentinel node biopsy procedure, the pathology, the surgery and the radiotherapy. Quality assurance procedures were initiated to guarantee a uniform quality of treatment between institutions. The surgical quality control consists of quality control before starting to include patients in the trial, regular site visits and axillary failure analysis by the Independent Data Monitoring Committee.

Before a centre is allowed to include patients in the AMAROS trial, the quality of the sentinel node procedure is checked. This requirement is based on the existence of a learning curve [5-7]. The surgeon and nuclear physician conducting the sentinel node procedure should have followed a training course. The trial protocol demands a so-called combined technique, using lymphoscintigraphy, preoperative blue dye injection and peroperative use of a gamma probe. At least 30 sentinel node procedures followed by an ALND of at least level I and level II have to be performed, with a minimum of 27 patients with accurate sentinel node identification. Not more than one false negative should be encountered. Besides inspection of the learning curve by an onsite review of 30 original patient files, the surgical quality control from the start consists of witnessing a lymphoscintigraphy and sentinel node biopsy procedure. So far $98 \%$ of the sentinel nodes have been identified, suggesting that the quality control is very effective. In addition, $63 \%$ of the sentinel node biopsies resulted in a negative sentinel node, which corroborates the superfluity of following axillary staging operations in the past.

The EORTC Radiotherapy Group has a strong tradition of institution-bound quality assurance [8-10]. Approval of the dummy run by the Radiotherapy Quality Assurance Committee is one of the prerequisites in the AMAROS trial. A recent study of the compliance of participating institutes to the radiotherapy guidelines of the AMAROS dummy run protocol resulted in a number of potential protocol deviations found at first assessment [11]. Since recommendations led to a large number of adaptations by the participants, a considerable improvement in protocol compliance and inter-institutional consistency was achieved.

The evaluation of disseminated breast tumour cells in sentinel lymph nodes by quantitative real-time PCR and the comparison of the sensitivity of this assay with the routine histological analysis is part of the translational research [12]. The quantitative real-time PCR assay with multiple mRNA markers for the detection of disseminated breast cancer cells in sentinel nodes resulted in an upstaging of sentinel nodes containing metastastic disease of $10 \%$ compared with the routine histological analysis. The application of this technique may be of clinical relevance, as it is suggested that micrometastatic disease in sentinel nodes is associated with further nodal nonsentinel node metastases in breast cancer.

More detailed information is available online (www.amaros.nl).

\section{The EORTC 10994 p53 trial (Breast International Group 00-01)}

The p53 study is the first prospective intergroup translational research trial assessing the potential predictive value of p53 using a functional assay in yeast in patients with locally advanced/inflammatory or large operable breast cancer prospectively randomised to a taxane regimen versus a nontaxane regimen. The EORTC Breast Cancer Group, the sponsor of the trial, collaborates in this trial with the Anglo-Celtic group, the SAKK (Swiss Group for Clinical Research) group and the Swedish group. Free drug supply (docetaxel) is offered by the pharmaceutical industry partner Aventis. Furthermore, the trial is supported by two grants from Aventis and Pfizer. Figure 2 depicts the scheme of the p53 study.

Factors predictive of the response to chemotherapy are virtually nonexistent. Experimental and clinical studies have shown that anticancer agents achieve their cytotoxic effect through apoptosis [13] and that p53 is a key gene in the apoptotic pathway. In vivo and in vitro data suggest that p53-mutated tumours are resistant to anthracyclines but remain sensitive to taxanes [14-20]. Limited clinical data suggest that this finding may be true in patients with breast cancer [21]. Unfortunately the immunohistochemistry method is not the best method to assess p53. There is a risk of false-negative and false-positive results when p53 is assessed by the immunohistochemistry method as compared with the sequencing method [22]. A functional assay for $p 53$ in yeast gives a direct information regarding p53 function (detects biologically important mutations) and is more sensitive than sequencing (it is 


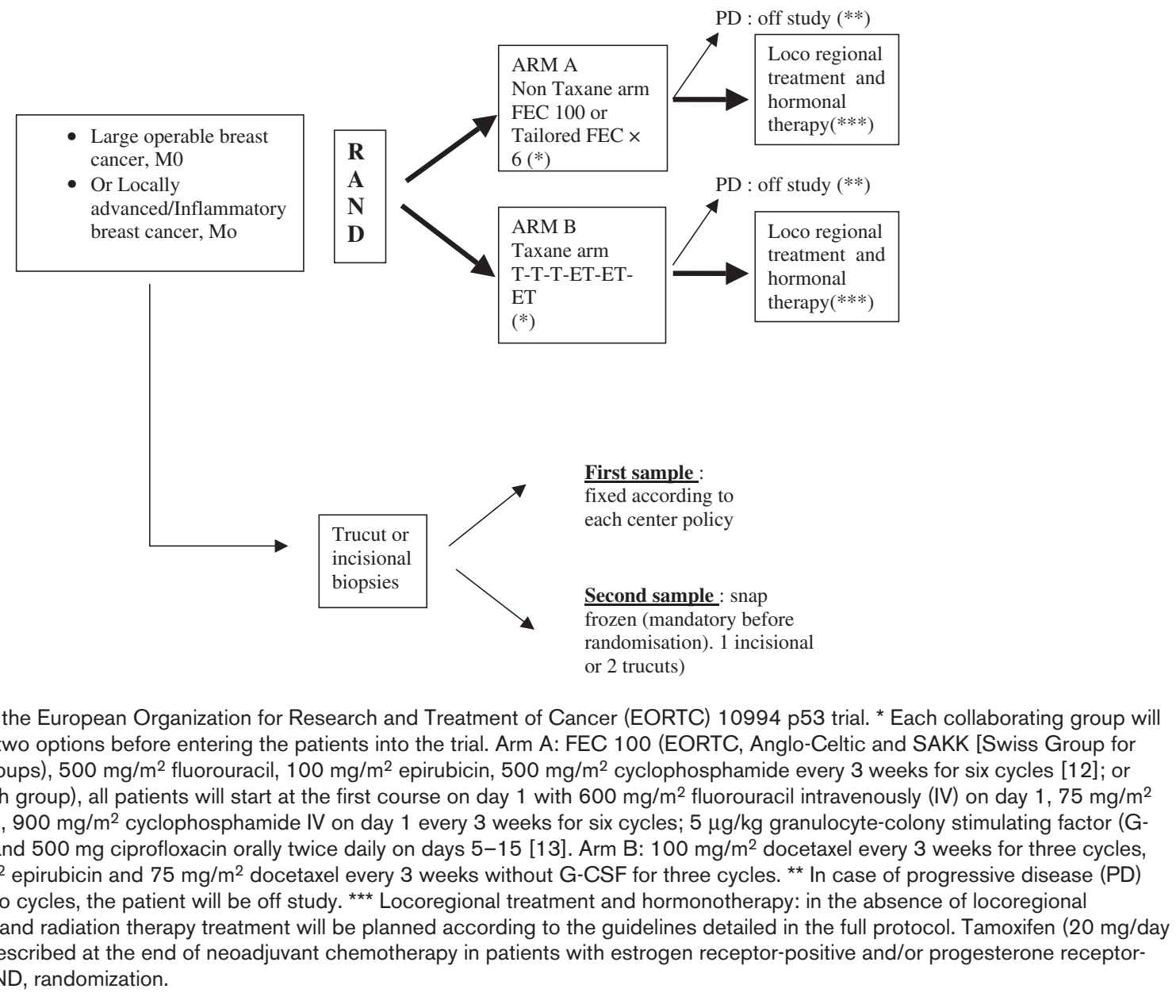

insensitive to contamination of samples with normal tissue) [23].

In this study we are comparing prospectively a nontaxane anthracycline-based regimen versus a taxane regimen. We are using the p53 functional test in yeast. We are performing this trial in the neoadjuvant setting, which allows one to assess clinical and pathological responses after chemotherapy. Patients with either large operable or locally advanced cancers or inflammatory cancers are eligible.

The primary endpoints consist of comparison of the progression-free survival (PFS) of patients who received neoadjuvant chemotherapy without taxanes (treatment $A$ ) with the PFS of patients who received a chemotherapy with taxanes (treatment B), in both the normal p53 subgroup and in the p53-mutated subgroup. In addition we will compare the PFS of patients who received treatment $A$ with the PFS of patients who received treatment $B$ independent of the p53 status. The secondary endpoints are distant metastasis-free survival, overall survival and (including $10 \%$ of ineligible or nonassessable cases). We have already included 960 patients.

An intermediate analysis is planned when all the patients will be included in the study (number of expected events, 158). This analysis will provide some information concerning the p53-mutated subgroup (80\% power to see an increase in the PFS of $30 \%$ in arm A to $50 \%$ in arm $\mathrm{B}$; hazard ratio, 1.76; alpha, 0.008), but it will be too soon to obtain on the normal p53 subgroup.

If the recruitment in this study is performed over a period of 3 years, three additional years will be necessary before the final analysis. There are no early stopping rules in this trial.

The primary endpoint of this trial is a translational research question: do p53-mutated tumours respond better to taxanes than p53 wild-type tumours? A frozen tumour sample is mandatory before entering a patient in this trial. We will therefore have ideal conditions to perform translational research studies. For example, we are trying to identify a cDNA microarray profile that can predict for a 
complete pathological response after treatment $A$ (anthracycline based) or treatment B (taxane based).

More detailed information is available online (www.eortc.be).

\section{Competing interests}

None declared.

\section{Acknowledgement}

The authors would like to thank the EORTC Breast Cancer Group for the financial support for the fellowship of PM, who is dedicated to the assessment of the quality control of surgical procedures in the EORTC 10981-22023 AMAROS trial.

\section{References}

1. Giuliano AE, Haigh PI, Brennan MB, Hansen NM, Kelley MC, Ye W, Glass EC, Turner RR: Prospective observational study of sentinel lymphadenectomy without further axillary dissection in patients with sentinel node-negative breast cancer. J Clin Oncol 2000, 18:2553-2559.

2. Veronesi U, Paganelli G, Viale G, Luini A, Zurrida S, Galimberti V, Intra M, Veronesi P, Robertson C, Maisonneuve P, Renne G, De Cicco C, De Lucia F, Gennari R: A randomized comparison of sentinel-node biopsy with routine axillary dissection in breast cancer. N Engl J Med 2003, 349:546-553.

3. Rutgers EJ: Sentinel node procedure in breast carcinoma: a valid tool to omit unnecessary axillary treatment or even more? Eur J Cancer 2004, 40:182-186.

4. Bourez RL, Rutgers EJ: The European Organization for Research and Treatment of Cancer (EORTC) Breast Cancer Group: quality control of surgical trials. Surg Oncol Clin N Am 2001, 10:807-819, ix.

5. Bass SS, Cox CE, Reintgen DS: Learning curves and certification for breast cancer lymphatic mapping. Surg Oncol Clin N Am 1999, 8:497-509.

6. Giuliano AE, Kirgan DM, Guenther JM, Morton DL: Lymphatic mapping and sentinel lymphadenectomy for breast cancer. Ann Surg 1994, 220:391-398.

7. Orr RK, Hoehn JL, Col NF: The learning curve for sentinel node biopsy in breast cancer: practical considerations. Arch Surg 1999, 134:764-767.

8. Bentzen SM, Bernier J, Davis JB, Horiot JC, Garavaglia G, Chavaudra J, Johansson KA, Bolla M: Clinical impact of dosimetry quality assurance programmes assessed by radiobiological modelling of data from the thermoluminescent dosimetry study of the European Organization for Research and Treatment of Cancer. Eur J Cancer 2000, 36: 615-620.

9. Horiot JC, Johansson KA, Gonzalez DG, van der Schueren E, van den Bogaert W, Notter G: Quality assurance control in the EORTC cooperative group of radiotherapy. 1. Assessment of radiotherapy staff and equipment. European Organization for Research and Treatment of Cancer. Radiother Oncol 1986, 6:275-284.

10. Johansson KA, Horiot C, Van Dam J, Lepinoy D, Sentenac I, Sernbo G: Quality assurance control in the EORTC cooperative group of radiotherapy. 2. Dosimetric intercomparison. Radiother Oncol 1986, 7:269-279.

11. Hurkmans CW, Borger JH, Rutgers EJ, van Tienhoven G: Quality assurance of axillary radiotherapy in the EORTC AMAROS trial 10981/22023: the dummy run. Radiother Oncol 2003, 68:233240.

12. Weigelt B, Verduijn $P$, Bosma AJ, Rutgers EJ, Peterse HL, Van't Veer $L$ : Detection of metastases in sentinel lymph nodes of breast cancer patients by multiple mRNA markers. $\mathrm{Br} J$ Cancer 2004, 90:1531-1537.

13. Hickman JA: Apoptosis induced by anticancer drugs. Cancer Metastasis Rev 1992, 11:121-139.

14. Fan S, Cherney B, Reinhold W, Rucker K, O'Connor PM: Disruption of p53 function in immortalized human cells does not affect survival or apoptosis after taxol or vincristine treatment. Clin Cancer Res 1998, 4:1047-1054.

15. Lanni JS, Lowe SW, Licitra EJ, Liu JO, Jacks T: p53-independent apoptosis induced by paclitaxel through an indirect mechanism. Proc Natl Acad Sci USA 1997, 94:9679-9683.
16. Lowe SW, Ruley HE, Jacks T, Housman DE: p53-dependent apoptosis modulates the cytotoxicity of anticancer agents. Cell 1993, 74:957-967.

17. Lowe SW, Bodis S, McClatchey A, Remington L, Ruley HE, Fisher $\mathrm{DE}$, Housman DE, Jacks T: p53 status and the efficacy of cancer therapy in vivo. Science 1994, 266:807-810.

18. O'Connor PM, Jackman J, Bae I, Myers TG, Fan S, Mutoh M, Scudiero DA, Monks A, Sausville EA, Weinstein JN, Friend S, Fornace AJ Jr, Kohn KW: Characterization of the p53 tumor suppressor pathway in cell lines of the National Cancer Institute anticancer drug screen and correlations with the growthinhibitory potency of 123 anticancer agents. Cancer Res 1997, 57:4285-4300.

19. Wahl AF, Donaldson KL, Fairchild C, Lee FY, Foster SA, Demers GW, Galloway DA: Loss of normal p53 function confers sensitization to Taxol by increasing G2/M arrest and apoptosis. Nat Med 1996, 2:72-79.

20. Woods CM, Zhu J, McQueney PA, Bollag D, Lazarides E: Taxolinduced mitotic block triggers rapid onset of a p53-independent apoptotic pathway. Mol Med 1995, 1:506-526.

21. Aas $T$, Borresen $A L$, Geisler $S$, Smith-Sorensen $B$, Johnsen $H$, Varhaug JE, Akslen LA, Lonning PE: Specific P53 mutations are associated with de novo resistance to doxorubicin in breast cancer patients. Nat Med 1996, 2:811-814.

22. Sjogren $\mathrm{S}$, Inganas $\mathrm{M}$, Norberg $\mathrm{T}$, Lindgren $\mathrm{A}$, Nordgren $\mathrm{H}$, Holmberg L, Bergh J: The p53 gene in breast cancer: prognostic value of complementary DNA sequencing versus immunohistochemistry. J Nat/ Cancer Inst 1996, 88:173-182.

23. Flaman JM, Frebourg T, Moreau V, Charbonnier F, Martin C, Chappuis P, Sappino AP, Limacher IM, Bron L, Benhattar J, Tada M, Van Meir EG, Estreicher A, Iggo RD: A simple p53 functional assay for screening cell lines, blood, and tumors. Proc Natl Acad Sci USA 1995, 92:3963-3967. 